\title{
Newborn care practices: A case study of tribal women, Gujarat
}

\author{
Baiju Dinesh Shah ${ }^{1^{*}}$, Laxmi Kant Dwivedi ${ }^{2}$ \\ ${ }^{1}$ Core Capability Group, Health and Public Services, Accenture Management Consulting, Mumbai, India; \\ ${ }^{*}$ Corresponding Author: dr.baijushah@yahoo.com \\ ${ }^{2}$ Department of Mathematical Demography \& Statistics, International Institute for Population Sciences, Mumbai, India; \\ laxmikdwivedi@gmail.com
}

Received 20 June 2013; revised 20 July 2013; accepted 10 August 2013

Copyright (C) 2013 Baiju Dinesh Shah, Laxmi Kant Dwivedi. This is an open access article distributed under the Creative Commons Attribution License, which permits unrestricted use, distribution, and reproduction in any medium, provided the original work is properly cited.

\section{ABSTRACT}

Plateaued rate of decline in neonatal mortality rate is one of the major obstacles in achieving Millennium Development Goal 4 especially in developing countries. Even in India, nationwide interventions targeting safe mother and newborn care have not yielded the desired impact, indicating the necessity to combat neonatal mortality rate at population specific level. The objective of this study is to identify the newborn care practices and beliefs, analyze their harmful or beneficial characteristics, describe the deviations from the essential newborn care practices during hospital/home delivery, explain barriers to care seeking and identify areas of potential resistance for behavior change; and utilize study findings to tailor-make cost-effective essential newborn care package. The study uses qualitative data from in-depth interview of mothers who had experienced neonatal death and key-informant interviews with healthcare personnel and birth attendants. 33 cases were randomly selected from the registered neonatal deaths across Bharuch district of Gujarat, India. Key finding of this study is less prevalent practice of essential newborn care among all cases irrespective of place of delivery and the health-care personnel facilitating delivery. Habitual traditional/tribal newborn care methods challenge the practice of prescribed essential newborn care. Clustering of deaths in few households added significantly to the existing burden of neonatal deaths, attributed to superstition "Ratewa" by tribal. Study has concluded that the introduction and implementation of essential newborn care at hospital and communityl household level are the need of the hour. Quality home based neonatal care through cost effective interventions is deemed necessary where accessing institutional care is not possible in the immediate term. Community health workers can contribute to the eradication of harmful newborn care practices and the sustenance of essential practices through community education and behavior change communication.

Keywords: Home Delivery; Institutional Delivery; Newborn Care Practices; Essential Newborn Care; Cost-Effective Interventions; Home Based Newborn Care

\section{INTRODUCTION}

Globally, there has been a considerable decline in under-five and infant mortality during last four decades. However, neonatal mortality rates remain unchanged especially in developing countries [1,2]. It is estimated that each year around four million neonatal deaths occur almost exclusively in low income countries [3]. In these countries, progress towards achieving Millennium Development Goal 4-"Reducing under-5 mortality from the 1990 baseline by two-thirds" is being hampered by slow progress in reducing the number of neonatal deaths [4]. The neonatal period is only $1 / 60^{\text {th }}$ of the first five years of life, but contributes 38 percent of the estimated 10.5 million under-five deaths occurring every year all over the world [5].

In India, government, bilateral and multilateral agencies have made several efforts in the area of maternal and child health welfare. The introduction of government schemes like Janani Suraksha Yojana, Chiranjeevi Scheme, 
Propagation of Emergency Obstetric Care (EmOC), Implementation of Integrated Management of Childhood and Neonatal Illness, etc. has resulted in an increase in institutional delivery and decrease in infant and child mortality rates. But there is no significant difference in neonatal mortality rates, as evidenced by analysis of infant and child mortality rates over the past decade. Table 1 provides a comparison of neonatal, post-neonatal, infant, child and under five mortality rates from past three National Family Health Surveys (NFHS).

Even though the primary causes of neonatal deaths are estimated to be preterm birth (28 percent), severe infections (26 percent), birth asphyxia and injuries (23 percent), tetanus (seven percent), congenital anomalies (seven percent) and diarrhea (three percent), with Low Birth Weight contributing to large proportion of neonatal deaths [5]; studies show evidence about contribution of care practices immediately following delivery to newborn's risk of morbidity and mortality [6]. Studies report that most newborns in low income countries like India die at home while they are cared by mothers, relatives, and traditional birth attendants [7].

In India, the practices of essential newborn care are not studied comprehensively and hence relatively less knowledge exists about the influence of practiced traditional newborn care practices on newborn survival. Studies on newborn care in some communities show that the knowledge and practice of basic newborn care for instance prevention of hypothermia, feeding of colostrum and exclusive breast-feeding are lacking; even awareness regarding care seeking on the identification of lifethreatening signs has been found to be very low [8]. Despite implementation of proven cost-effective solutions such as promoting antenatal tetanus toxoid immunization, skilled attendance during delivery, immediate and exclusive breast-feeding, and clean cord care; there has been relatively little change in neonatal mortality rate (NMR) [9].

The World Health Organization recommends improving essential newborn care practices at birth in order to reduce neonatal morbidity and mortality [10]. Effective promotion of essential newborn care at scale could sig- nificantly contribute to reducing the leading causes of newborn deaths in low income countries, especially those due to sepsis/pneumonia, preterm births and tetanus [6]. The essential practices include clean cord care, thermal care, initiating breast-feeding immediately or within an hour after birth, skilled assistance at birth for resuscitation, care-seeking and extra care for sick and underweight babies. Two Lancet series, on newborn health and maternal health propose key evidence-based interventions and packages which, if implemented to scale, could greatly contribute to saving maternal and newborn lives in low income countries. These interventions emphasize strengthening the continuum of maternal, newborn and child care during the antenatal, natal and postnatal phase [1,11].

Literature suggests that the challenge for reducing neonatal deaths in any developing country requires solutions through research to inform program innovation and action oriented policies designed to improve newborn health and increase their probability of survival [12]. Implementation of an effective program for the promotion of childbirth and newborn care practices requires understanding of the community and household traditional newborn care practices. Such information will enable the development of programs which promote culturally sensitive and acceptable change in practices. Information about reasons for delivering at home, preference of traditional birth attendant for delivery and newborn care practices is lacking from rural tribal areas of India, which is necessary for healthcare planners to design health services. The objective of this study is to describe the deviations from the essential newborn practices followed during hospital and home delivery. Study also explores the tribal specific home based newborn care practices during the antenatal, intranatal and postnatal care period and assesses its impact on the morbidities of neonate and hence the neonatal health outcomes. It also identifies the socio-demographic, antenatal and delivery care factors associated with these practices; along with understanding of care seeking behavior of mother and family members. This study by analyzing the newborn care practices in the rural tribal study area of "Gujarat" has made an attempt

Table 1. Percentage of early childhood mortality rates for the five-year period preceding the surveys, NFHS-1992-1993, NFHS1998-1999 and NFHS-2005-2006.

\begin{tabular}{ccccc}
\hline Early Childhood Mortality Indicators & NFHS-1992-1993 & NFHS-1998-1999 & NFHS-2005-2006 & $\begin{array}{c}\text { Percentage Decrease from } \\
\text { NFHS-1992-1993 to } \\
\text { NFHS-2005-2006 }\end{array}$ \\
\hline Neonatal Mortality Rate & 49 & 43 & 39 & 25.64 \\
Post-Neonatal Mortality Rate & 30 & 24 & 18 & 66.67 \\
Infant Mortality Rate & 79 & 68 & 57 & 38.60 \\
Child Mortality Rate & 33 & 29 & 74 & 83.33 \\
Under Five-Year Mortality Rate & 109 & 95 & & 47.30 \\
\hline
\end{tabular}


to recommend the desired interventions necessary for improving the newborn survival which are cost effective and which can be practiced by healthcare personnel irrespective of place of delivery.

\section{MATERIALS AND METHODS}

The present study was conducted in a block of Bhauch district of Gujarat wherein the population constituted 79 percent of "Bhil" tribe population, who are considered to be among the oldest settlers in the country. They have their own typical mode of thinking, feeling and common beliefs and attitudes, sentiments and ideals. As members of the scheduled tribes, they have distinctive social identities and face different forms of social and economic discrimination. Hence within this population and tribal entity, differences in dialect, health practices, unique customs, values and traditions are apparent. This study was undertaken during period from May, 2009 to November 2009.

For case studies the block was divided into different sectors (sector being the panchayats of that block) to explore all possible newborn care practices and other contributing factors for neonatal deaths in the district. Of total 106 neonatal deaths randomly selected from the list available from Non-Government Organization sampling frame (i.e. registered neonatal deaths in years 2008 and 2009), 33 deaths had been selected randomly for case studies considering the sectors (the distribution of the sampling frame and sample of neonatal deaths is shown in Figure 1).

The data for case studies was collected using different interview techniques, with in-depth interview of mothers who had experienced neonatal death (primary respondent), and whenever possible even of an adult relative who had the closest contact with the child during terminal illness (secondary respondent). Key-informant interviews were conducted with four healthcare personnel (two medical doctors and two community health

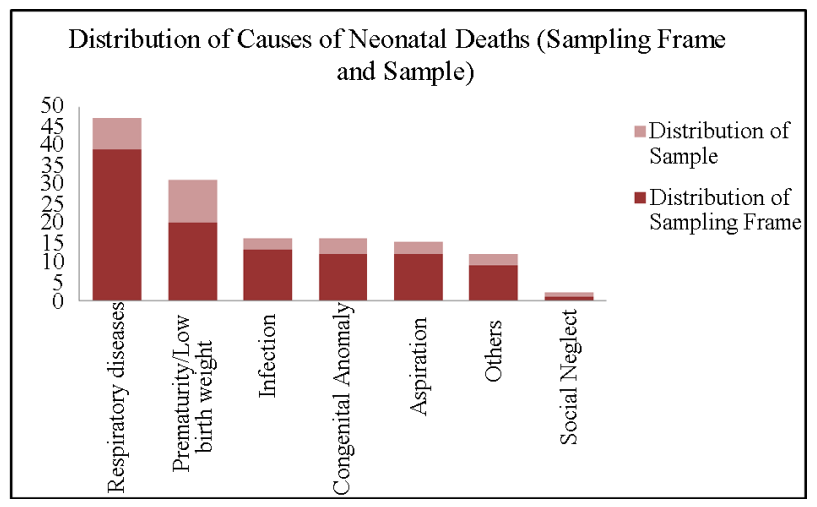

Figure 1. Distribution of causes of neonatal deaths (sampling frame and sample). workers and four birth attendants (out of which two were trained birth attendants and other two were untrained birth attendants).

The data collection tool or questionnaire for in-depth interview consists of two parts. First part has information related to socio-economic, maternal, birth and delivery related factors. The second section has information of essential newborn practices followed during delivery, neonatal death history and traditional newborn care practices. The questionnaire was adapted from the available guidelines of World Health Organization verbal autopsy questionnaire for investigating neonatal deaths with added questions on socio-economic profile, maternal, pregnancy and child-birth factors. The instrument was further adapted to local context and culture. The questionnaire started with close ended questions followed by open ended questions to elicit a narrative about neonate's death. The researcher obtained an informed consent from all the participants before conducting the interview. The data collection was done by researcher herself (from medical background). During data collection, interviews were conducted in Gujarati using local vocabulary.

Analysis of the in-depth interviews and Key Informant interviews was done using latent thematic content analysis. Transcripts were first read several times to get an overall picture and then meaningful units were coded, condensed and categorized into broad themes [13]. Analysis is presented in three sections which include analysis of current practice of various components of essential newborn care and traditional newborn care practices during the antenatal, natal and postnatal phase. Barriers to care seeking were characterized according to the three delay model which includes delay in deciding to seek care, delay in reaching the health facility, and delay in receiving care once at the health facility $[14,15]$.

\section{FINDINGS}

\subsection{Practice of Essential Newborn Care Practices}

Essential newborn practices that were not followed in the hospital and home births among the neonatal deaths are listed in Table 2.

\subsubsection{Institutional Delivery}

Of the 33 cases, hospital births accounted for 66 percent. The incidence of home delivered neonatal deaths was high among Muslim families because of prevalent belief that hospital for deliveries should be accessed only in the absence of traditional birth attendant alias "Dai" or in instances of postpartum complications. Even among women who had accessed health facility for delivery, the reasons for preference of Institutional delivery were: all the Dai's in our village have either died or migrated, no 
Dai is left in the village and hence we had no option other than institutional delivery. It was quite surprising to find that the mothers usually did prefer institutional delivery, but the decision was subdued by family members.

\subsubsection{Skilled Attendance for Delivery}

Table 3 shows attendance at birth among institutional and home deliveries. Home deliveries show uniform distribution in attendance at birth by trained and untrained birth attendants.

\subsubsection{Cord Cutting and Cord Care}

Cord cutting is of particular interest generally being indicative of obstetric care. In home births the primary birth attendant usually does cord cutting and cord clamping with a spectrum of instruments (cord cutting was done with used shaving blades, household knives and sometimes Dais had their special equipment for cord cutting; while cord clamping was mostly done with used rough cloth).

A good practice was found that cord cutting was not done after the placenta is delivered as evidenced in other parts of India [16]. There was no inquiry possible of practice in case of retention of placenta because no such case was recorded. For essential newborn care, in general strict care of the cord is not a norm unless there is Om- phalitis (infection of the umbilical cord stump in the neonatal newborn period) but families may apply something depending on availability. Among case studies, mostly cord application involved usage of an antiseptic powder provided by local Non-government organization.

\subsubsection{Airway Cleaning \& Resuscitation}

Use of mucus aspirator during home deliveries and suction in hospital births is a practice required for all neonates irrespective of whether suffering from birth asphyxia or not; as a primary resuscitation practice. Among hospital births, this primary resuscitation practice was followed in all cases but among home deliveries, mucus aspiration was done by Dai's finger with pinch of salt on it. Also household cloth was used for airway cleaning among most home births in study area.

\subsubsection{Thermal Care (Wrapping \& Skin-to-Skin Care)}

Wrapping of newborn immediately after birth is necessary for prevention of hypothermia which is one of the prime causes of neonatal deaths. Non-wrapping of neonate was frequent among home delivered neonatal deaths. The prime reason of non-wrapping being the newborn care practice of "Chatti puja"; wherein the child is not draped until the seventh day of his life. In essential

Table 2. Non-practice percentage of essential newborn care during delivery.

\begin{tabular}{ccc}
\hline Essential Newborn care practice & Home Deliveries $(\mathbf{n}=\mathbf{1 3})$ & 27.3 \\
Wrapping & 72.7 \\
Thermal Care & 63.6 \\
Airway Cleaning & 81.8 \\
Resuscitation Mucus Aspirator or Suction & 63.6 \\
Immediate Breast-feeding & 63.6 \\
Burping & 63.6 \\
Cord Care-Sterilized Scissors & 45.5 \\
Cord Clamp-Therapeutic thread & 54.3 \\
Eye Care-Cotton Swab & 5.5 \\
\hline
\end{tabular}

Table 3. Skilled attendance during delivery.

\begin{tabular}{|c|c|c|}
\hline Healthcare Personnel & Home Delivery (\%) & Institutional Delivery (\%) \\
\hline Government Doctor & 0.0 & 64.0 \\
\hline Auxiliary Nurse Midwife/Nurse & 0.0 & 18.0 \\
\hline Trained Birth Attendant & 45.5 & 0.0 \\
\hline No Attendant & 9.0 & 0.0 \\
\hline Total & $100.0(\mathrm{n}=13)$ & $100.0(\mathrm{n}=20)$ \\
\hline
\end{tabular}


newborn care, immediately after the resuscitation process, the newborn is handed to mother who does continuous "rooming in" with the neonate which is also an essential newborn practice to avoid hypothermia commonly known as "Kangaroo Mother Care" or Skin-to-skin care. The Skin-to-skin care was not practiced in majority of cases irrespective of place of delivery. Delayed bathing was a common practice among all home births whereas nonbathing of the newborn until 7 days was prevalent. Instead of bathing, among home births wiping the baby with cloth soaked in lukewarm water was the recommended practice by elderly.

\subsubsection{Breast-feeding}

In the recent century importance of immediate breast-feeding of colostrum is widely recognized all over the world. But still it was not practiced in almost 63 percent of cases irrespective of place of delivery, because most of the mothers were of the opinion that colostrum is difficult to digest by newborn and will create a lump in abdomen, "dudhnuchikbalak ne pachenahi, toh bi aenelevamaaaave to pet ma gaathtayarthai, je davathibhisaajinaathay".

Hence, breast-feeding of the neonate was started only on the 3rd day after birth even if it is a Low birth weight neonate. Till the third day instead of breast-feeding, neonate is given "Gadthuti" (a form of pre-lacteal feed) of sugar water or in some instance even sugarcane juice was given. If the mother has feeding problems then goat's milk is preferred for top feeding rather than cow's milk. Untrained birth attendants usually advised to start breastfeeding only after third day of birth. Burping is an essential practice to avoid neonatal deaths due to aspiration of milk and food, to be practiced after every breast-feeding. Burping was not practiced among all neonatal deaths irrespective of place of delivery pointing to the negligence of the hospital nurses and community health workers in creating awareness about the importance of the practice.

\subsection{Role of Untrained Birth Attendants in Neonatal Care}

Table 4 enlists the untrained birth attendant's way of practicing essential newborn care. Extreme trust for Dai was well evidenced by instances such as "If Dai suggests no need for hospital care then neonate is neither admitted to Neonatal Intensive Care Unit nor sought postnatal care". Trust persists even if Dai uses house knife for cord cutting \& household cloth for throat clearance. But instances were recorded when eventually after the neonate death family members did attribute the cause of neonatal death to the unsafe neonatal care practice of Dai. For example in one case mother and relatives said that during labor pains Dai massaged mother's abdomen therefore neonate died i.e. "Dai pet chodyu aetle balak marelu janamyu hatu".

\subsection{Traditional Beliefs and Practices among Case Studies during Pregnancy and Newborn Care}

Antenatal care: Perception was prevalent that sonography machine pressurizes fetus and leads to growth retardation or undetected congenital anomalies, "Sonography thi balak dabi jaaye, ane vadhe nahi”. Belief persists that if during first two pregnancies, complete antenatal care was done then it is not necessary to repeat it for the third pregnancy. In case of unmarried pregnancy no antenatal care check-up is done from the maternal house until the girl is accepted as a bride in paternal house. In most of the cases, it was found that pregnant women considered iron folic acid tablets or blood transfusion harmful for their fetus and therefore refused consumption even in cases of significantly low hemoglobin levels. Deliberate attempts of intake of iron folic acid tablets led to complaints of iron folic acid induced vomiting. A belief is prevalent among community that if there is amniotic discharge in the eighth month of pregnancy then it causes reduction in the size of fetus i.e. "Aath ma mahine paani padiyu, aetle balak sukai gayu". Cases of eighth month delivery have no chances of survival of neonate therefore no treatment required i.e. "Aath ma mahine shuvavd thay to balak na bachvana koi asar nahoy aetle aeni dava karavi jarori nahoy".

Mothers from this tribe believe that reduction in amount of food intake and also eating in small size plate during pregnancy leads to small size of baby's head and small placenta which facilitates easy labor. Some food items were restricted during pregnancy such as papaya, brinjal, jaggery etc. because of their perceived potential to induce abortion ("garam pade toh kashvavad thai"). It is also perceived that intake of milk and curd in large amount causes deposition of white layer on the body of neonate "thandu pade toh balak na sharir par cough chipki jaaye". Previous day's cooked food does not provide nutrition to child during pregnancy "Vaasi khaiye toh khadhelu balak ne asar naa kare". Pregnant women continue fasting ("Shankar-Parvati vrat", "Aekvira vrat" and "Dashma vrat") during pregnancy, even if it includes five days of fasting a week. These common perceptions about dietary habits among all case studies resulted in low body mass index among most of pregnant and delivered females. The dietary restrictions of mother increased in case of history of infant deaths especially on intake of non-vegetarian food, "maa ne rateva chey toh mansahar na levay".

Intranatal care: Birth weight of the neonate should not be recorded under any circumstances as it will cast an evil eye on the neonate and negatively impact survival 
Table 4. Neonatal care practices of untrained birth attendant.

\begin{tabular}{cl}
\hline Wrapping & Non-wrapping, no advice about "rooming-in" \\
Cord cutting & Regular shaving blade or household knife \\
Cord clamp & Household cloth \\
Eye care & Not practiced \\
Cleaning the airway & Cleaning with salt on Dai's finger \\
Colostrum & Not to be fed \\
Breast-feeding & Initiate only after third day of birth, no counseling about burping \\
\hline
\end{tabular}

and well being of child. Non-government organization based First Referral Unit was the last option for treatment of neonate and no further referral advice was followed even if the Non-government organization doctors had suggested referral.

Postnatal care: Mother should consume only roti and black gram during postnatal care, if she eats anything else it will lead to infection of umbilical cord of neonate, "Rotli ane mag khavanu biju khaiye to naidopake". A common belief of "Chatti Puja" i.e. till seventh day of birth, neonate should neither be wrapped with clothes nor exposed to sunlight, "Chatthi puja sudhi balak ne kapda naa pehravay ane tadko naa dekhaday". In some cases gender related neglect of care seeking was found because of increased expenditure for seeking specialized healthcare. Information related to immunization status could not be extracted as most of neonates had died within first week of life. Some Muslim families considered immunization as harmful to their neonate's health and even elderly in the house considered it unnecessary.

\section{DISCUSSION}

High number of mothers preferring institutional births in the study area does not represent a positive trend because hospital delivery was preferred as no Dai were left in village (either they had migrated or died). It also indicates chances of shift of preference to home deliveries with availability of Dai. But instances among some mothers for preference of institutional delivery create an opportunity window to reciprocate shift. Decision of hospital delivery only after realization of possible delivery or neonatal complication is also one of the negative factors. Villages with predominant Muslim population recording zero institutional births require targeted behavior change interventions.

Case studies indicate that pregnant women and their relatives show no distinction between trained and untrained birth attendant and access decision was based on the availability and accessibility of the identified birth attendants. In villages with predominant Muslim community, a single woman was deemed responsible for conducting all home deliveries. Birth attendants (irrespective of training) were entirely responsible with partial assistance of relatives in conducting delivery in the study area. However, in some communities of Northern India, Trained birth attendants often do not get involved until after delivery, which is usually carried out by a family member, i.e. Trained birth attendants are at least certainly not in full charge [17]. It was also interesting to note that all the trained and untrained birth attendants were referred by a common name "Daayanben"- attempt is required to help mothers and relatives distinguish between trained and untrained birth attendants and realize the implication of delivery from both personnel. Many studies report that the term trained birth attendants is rarely used locally as there is no such clearly defined group, and it stems partly from use by government in their training programs [18].

In the study area, untrained birth attendants or even in some instances the Trained birth attendants's practice their own traditional way of intra-natal and neonatal care which many a times conflicted to those recommended by the essential newborn care package [19]. Instances were recorded that families have awareness that some neonatal deaths are attributed to the faulty practices of the birth attendants which signifies that the birth attendants can be both stigmatized and revered for their work [18].

A wide variety of newborn care practices have been documented in the study area. Traditional practices have the advantage of being affordable, culturally acceptable and relevant to the local environment and socio-cultural needs for enhanced usage by most of the population. However, practices like "chattipuja" which are intended for good neonatal health pose a potential harm to the newborn due to the related risky traditional methods.

Cord cutting and clamping practices have been identified as risk factors for neonatal infection [6,20,21]. A study in rural India reported that regular antenatal care and skilled attendance at delivery was significantly associated with clean cord care and early breast-feeding, but not with thermal care [22]. Some studies show low coverage of clean cord care practices among home deliveries in South Asia [23-25]. In the study area cord care was not practiced during delivery among home births; but in postnatal stage cord care was done with an antiseptic 
powder provided free of cost by the local Non-government organization. Maintaining good thermal care at birth is crucial for preventing hypothermia, hypoglycemia and neonatal infections. Regarding prevention of hypothermia, it was found that wrapping was not practiced among home births while skin-to-skin care was not practiced in all home births and few institutional births. Currently, skin-to-skin care is recommended for all neonates [26]. In addition, where it is recommended that babies should be bathed no earlier than 24 hours after birth, it was found that delayed bathing or non-bathing till seven days after birth was a common practice among home and institutional births. Both practices of nonwrapping as well as delayed bathing are result of a traditional belief of "chattipuja".

Delayed breast-feeding especially up to three days was common and non-feeding of colostrum was recorded in all home births. This is a negative factor because if neonates are not breastfed within the first one hour of birth then it puts these neonates at an increased risk for death [27]. Pre-lacteal feeding was found universal i.e. prelacteal feeds were given for all home and institutional births. Many studies from India and other South Asian countries have indicated that women commonly wait for several days after birth to begin breast-feeding, avoid giving colostrum, or supplement breast-feeding with other food or liquids [28,29]. However findings from present study compare poorly with recent studies from Nepal, Pakistan and Bangladesh which shows early breast-feeding initiation rates of 91 percent, 73 percent and more than 90 percent respectively $[25,30,31]$.

Practices related to airway cleaning and resuscitation might be the cause of respiratory disorders especially pneumonia among neonates [32] because in many home births household cloth, salt on Dai's finger were used instead of mucus aspirator. Here mucus aspirator usage is emphasized because the local Non-government organization provides mucus aspirator free of cost along with training on its usage to all the community based health workers. Quantitative findings indicate that perinatal birth asphyxia was a commonest cause of perinatal mortality in this area [33].

Intra natal care and post natal care are crucial phases for survival of neonates. In the study area women have reported many reasons for not attending hospitals or primary healthcare centers for post natal care. These reasons are explained using the expanded "three delays model" $[14,15]$, wherein the first delay is in making the decision to seek care, the second is in reaching the health facility, while the third is in receiving adequate care in the facility. Socio-cultural factors and perceived benefit from healthcare facility usage influence the decision to seek care. Economic and physical accessibility mainly influence whether the woman actually reaches the facility (and perceived accessibility also influences deci- sion-making). Furthermore, this framework considers how clustered community attitudes create a more or less encouraging environment for family decision making. The location of residence influences most other factors. Figure 2 describes the barriers to seeking neonatal-care according to the three delays model as captured in the study area which include knowledge barriers; cultural, traditional beliefs and practices; financial constraints; issues related to 108 ambulance and other accessibility issues; peer influence of choice of care; service delivery gaps and some provider related factors as described in Table 5.

In this study a fourth delay is added because majority of critical newborn case families were advised secondary referral by the healthcare provider and still they had not accessed any other health facility.

A matter of concern is the clustering of deaths in few households which added significantly to the existing burden of neonatal deaths in the study area. Among these clustered neonatal deaths, most of the deaths had occurred within the time frame of 0 - 3 days after birth. Low birth weight/prematurity was the major cause of death irrespective of place of delivery pointing towards need of availability of necessary treatment modality. Study indicates that the probability of survival of index child highly depends upon the survival status of the preceding child. Some researchers are of the opinion that death clustering is purely a biological and social phenomenon, while some indicate influence of non-visible factors such as genetics [34] or close cousin marriages for child survival. Among case studies, many tribal women had pointed existence of clustering of deaths among their tribe, which is commonly referred as "Ratewa". Little variation was observed among these clustered families according to the social and economic variables because they belonged to the similar social hierarchy and occupation. The biological factors of Low birth weight and premature delivery in these families with undernourished mothers cannot be negated as a contributing factor for clustering of neonatal deaths [35]. Figure 3 highlights in a consolidated manner the direct causes, indirect causes (household/community level) and causes at society level for the cyclicality of neonatal deaths among these scarred families of the community, according to the observations and recordings of the case studies.

\section{CONCLUSIONS}

Ensuring universal access to skilled care is the accepted strategy to make childbirth and the early postnatal period safe for mother and newborn. While additional skilled attendants are being trained and deployed, health systems strengthened, and demand for appropriate care increased; a simultaneous strategy supporting community-based providers can help save lives in near future, 


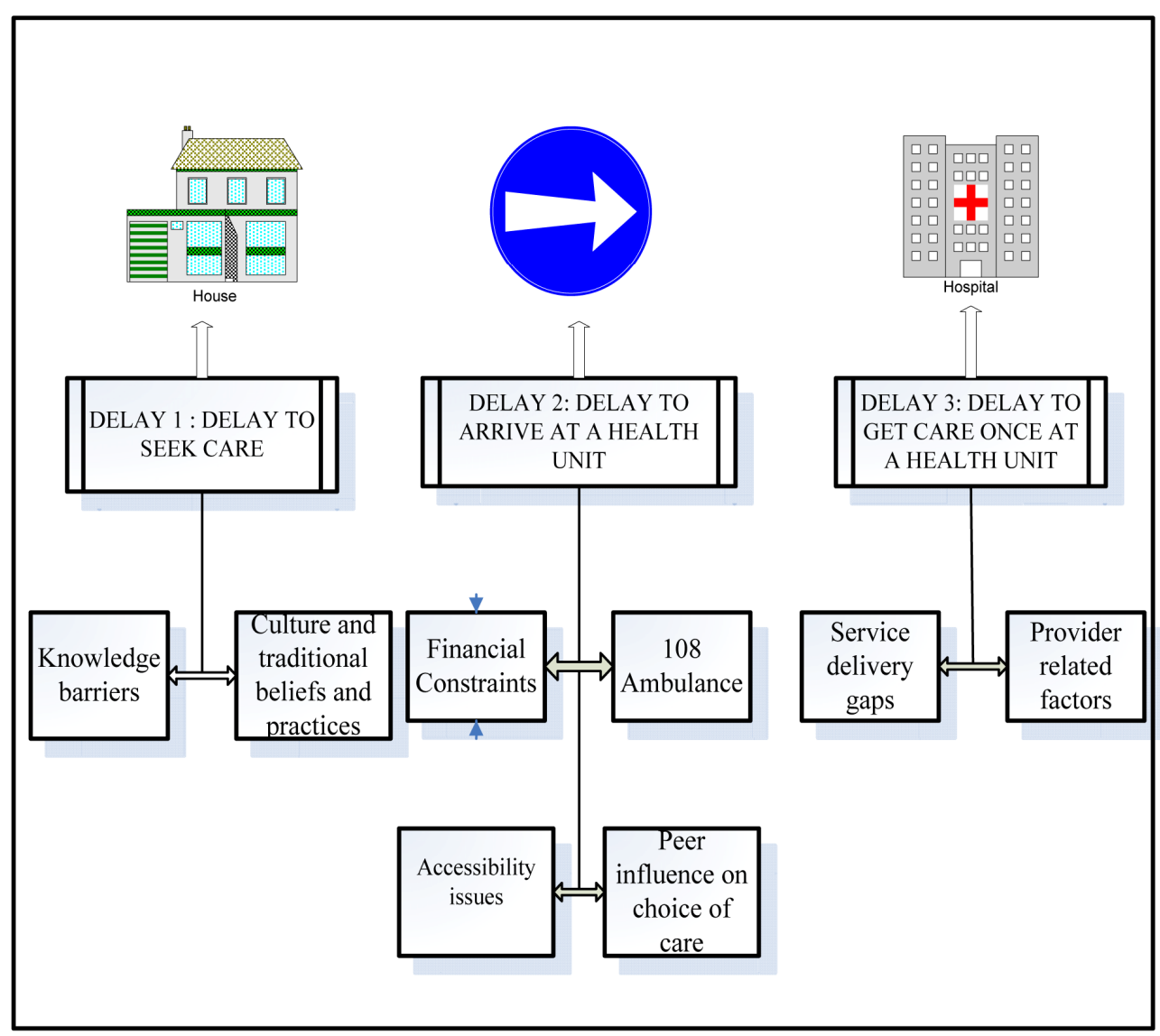

Figure 2. Three delay model of seeking neonatal care.

Table 5. Three delay model of seeking neonatal care.

\begin{tabular}{|c|c|}
\hline \multicolumn{2}{|r|}{ DELAY 1: DELAY TO SEEK CARE } \\
\hline Knowledge barriers & - Delay in identification of signs of disease \\
\hline Culture and traditional beliefs and practices & $\begin{array}{l}\text { - Decision making in the hands of birth attendants } \\
\text { - Limited community knowledge on importance of attending postnatal care }\end{array}$ \\
\hline \multicolumn{2}{|c|}{ DELAY 2: DELAY TO ARRIVE AT A HEALTH UNIT } \\
\hline Financial constraints & $\begin{array}{l}\text { - Lack of money for transport and hospital related costs (including under the table pay- } \\
\text { ments) } \\
\text { - Total reliance for transport on } 108\end{array}$ \\
\hline 108 Ambulance & $\begin{array}{l}\text { - No phone booths in some villages to call } 108 \\
\text { - Arrival time of } 108 \text { Ambulance differs from time to time }\end{array}$ \\
\hline Accessibility issues & $\begin{array}{l}\text { - During monsoon, connectivity of some villages to roads is lost and hence } 108 \text { Ambu- } \\
\text { lance become inaccessible }\end{array}$ \\
\hline Peer influence on choice of care & $\begin{array}{l}\text { - Women relying on other older women/mother-in-law/birth attendants for advise on } \\
\text { postnatal care attendance }\end{array}$ \\
\hline \multicolumn{2}{|c|}{ DELAY 3: DELAY TO GET CARE ONCE AT A HEALTH UNIT } \\
\hline Provider related factors & $\begin{array}{l}\text { - Technical inefficiency of doctor (for risk identification in neonate and while imparting } \\
\text { the required treatment modality to the patient) }\end{array}$ \\
\hline
\end{tabular}

especially in poor, low resource and high mortality settings. Community based health workers have a major role to play in the eradication of harmful newborn care practices and the sustenance of good practices and also prove to be a link between families and health system.
Emphasis for provision of essential newborn care at both health facility level as well as community/household level is required. Essential newborn care should start during pregnancy with Tetanus toxoid immunization, proper nutrition including iron/folate supplements, 


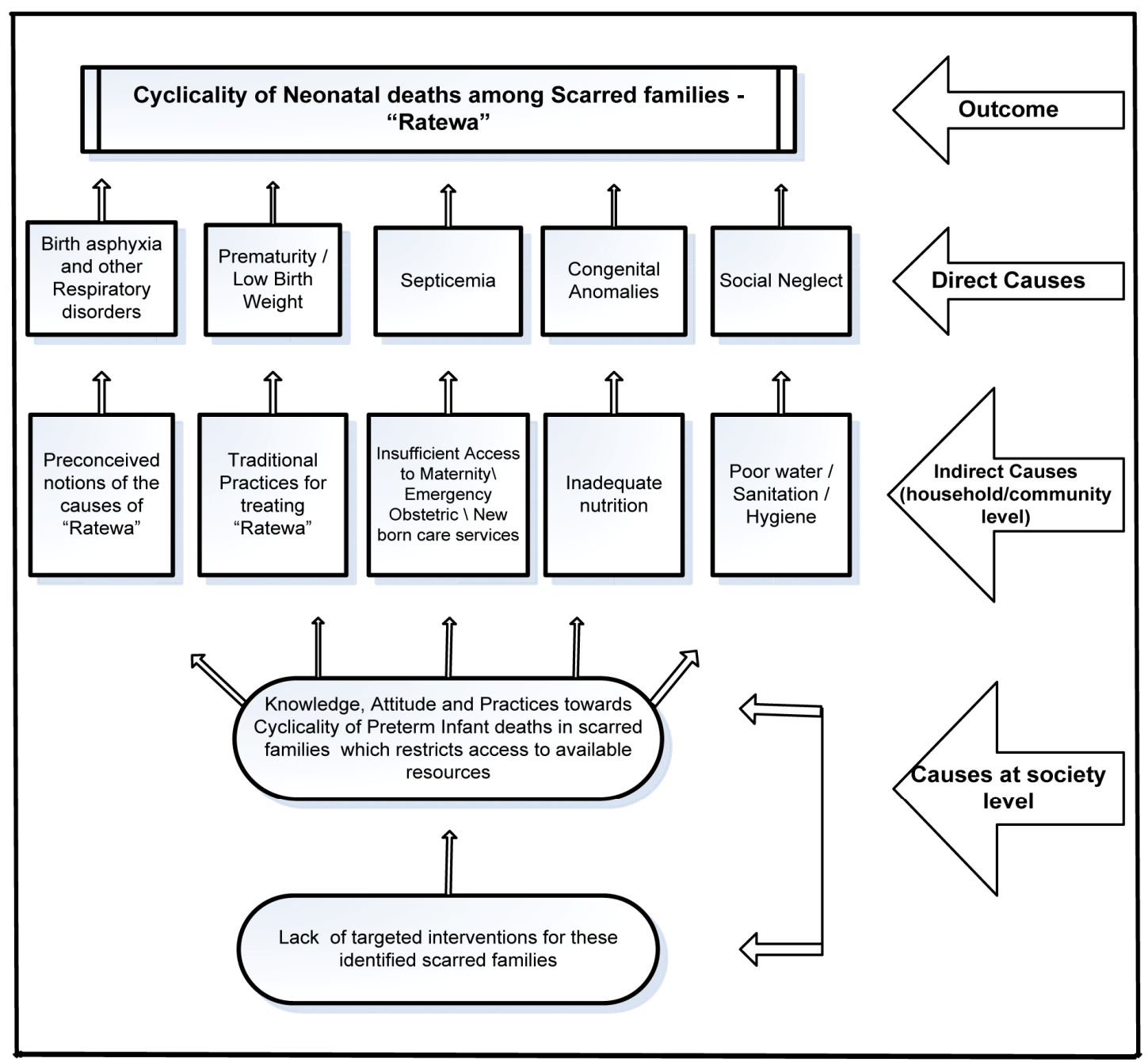

Figure 3. Causes of neonatal deaths among scarred families.

and treatment of maternal infections, such as malaria and sexually transmitted infections which have a strong influence on newborns' health and survival. Two priority interventions during labor and delivery are reducing the risk of infection to mothers and newborns and resuscitating newborns with breathing problems. Definite actions are required to increase the survival chances of newborn during post natal care phase. It can be achieved by emphasizing practice of immediate and exclusive breast-feeding, keeping the newborn warm and cleaning umbilical cord under supervision of a trained health-care provider. In addition to counseling on the practice of essential newborn care practices, effective medical management of low birth weight newborn and prematurity cases with timely diagnosis and immediate treatment follow-up is cardinal.

Figure 4 shows the areas of essential newborn care interventions for the study area. Only the identification of essential newborn care package is not sufficient, the need of the hour is implementation and sustenance of practice of essential newborn care package at the hospital as well as the community or house-hold level. This requires a two pronged strategy:

1) Focusing on quality of care in areas with a higher proportion of institutional births;

2) Develop cost effective interventions to provide quality home based neonatal care where accessing institutional care is not possible in the immediate near term.

These strategies need to be customized for the study area depending on the infrastructure, availability of resources and newborn health care need assessment. In low resource settings these strategies can be implemented in a phased manner.

Eradication of harmful newborn care practices and sustenance of good practices are not possible in immediate term without behavior change communication and regular counseling of mothers and relatives to impart knowledge of practice of essential post natal care. Teaching aids for mothers and relatives and frequent home visits by community health workers serve as an effective 


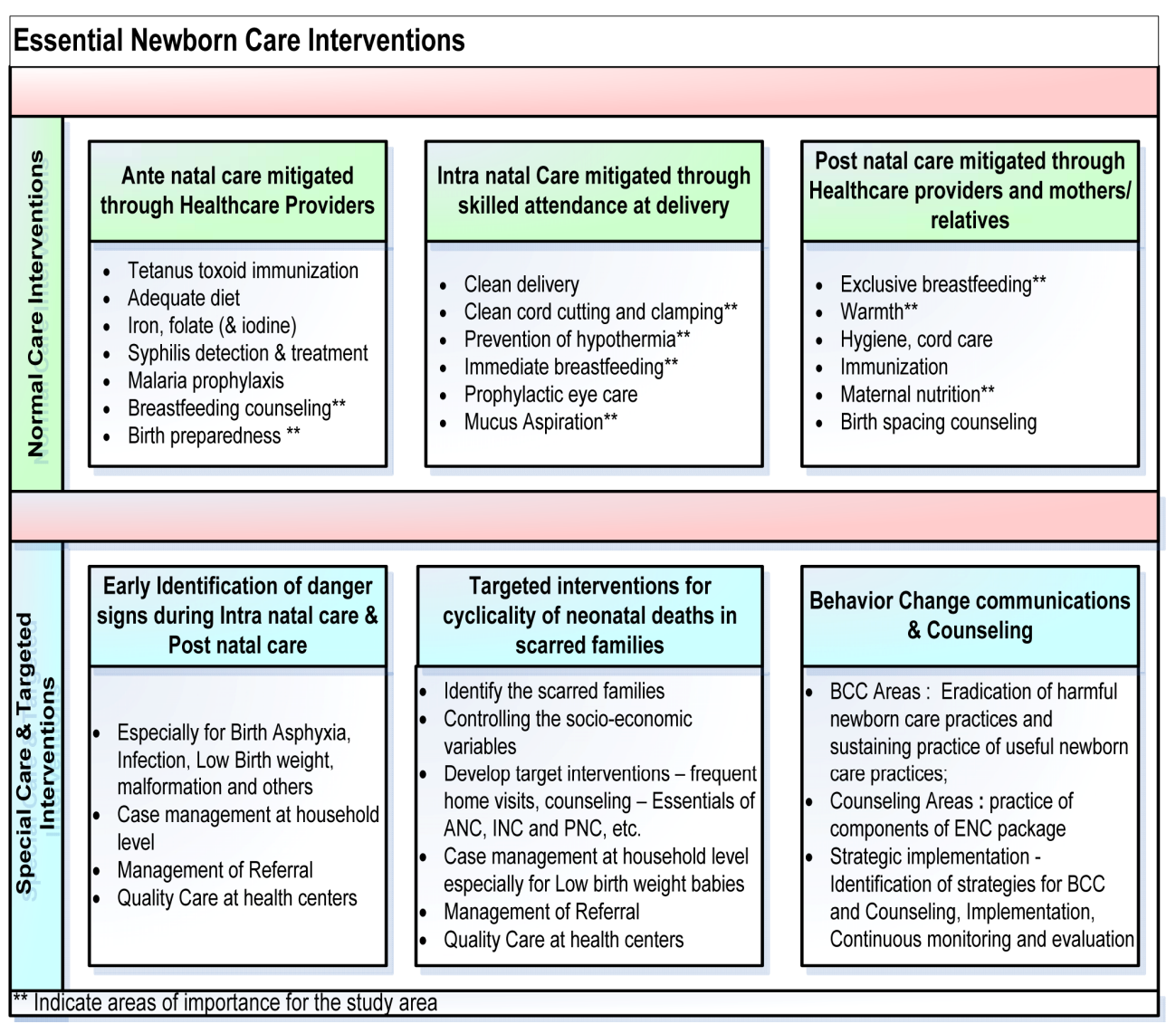

Figure 4. Essential newborn care interventions.

method of counseling. The strategies for behavior change communication and counseling can be deployed in a phased manner to have a sustained impact. Continued information, education and communication initiatives will help maintain belief of positive impact of the introduced essential newborn care interventions.

Introduction of targeted interventions is required to reduce cyclicality of neonatal deaths among the unfortunate scarred families by controlling the socio-economic variables, referral management and case management at household level especially for Low birth weight babies.

\section{POLICY IMPLICATIONS}

Only introduction or implementation of above stated newborn care interventions is not sufficient to improve newborn health and survival in the immediate as well as long term. Policy level commitment is required to integrate such type of interventions in existing healthcare programs considering the share of neonatal deaths among Under 5 mortality. An implementation plan should be developed based on analysis of maternal and newborn health status, existing services, and newborn care practices; with agreement on objectives and priorities among relevant stakeholders. Interventions to improve newborn health should be integrated with the existing maternal and child healthcare programs. Research into attitudes and dynamics of decision-making at family and community levels will contribute to improved newborn care practices and appropriate use of services. Even after efficient deployment of interventions continuous monitoring and evaluation will help developing and sustaining effective interventions.

\section{REFERENCES}

[1] Tinker, A., Hoope-Bender, P., Azfar, S., Bustreo, F. and Bell, R. (2005) A continuum of care to save newborn lives. Lancet, 365, 822-825. doi:10.1016/S0140-6736(05)71016-3

[2] Arulampalam, W. and Bhalotra, S. (2006) Sibling death clustering in India: State dependence vs. unobserved heterogeneity. IZA Discussion Paper No. 2251.

[3] Black, R.E., Morris, S.S. and Bryce, J. (2003) Where and why are 10 million children dying every year? Lancet, 361, 2226-2234. doi:10.1016/S0140-6736(03)13779-8

[4] Bryce, J., Daelmans, B., Dwivedi, A., Fauveau, V., Lawn, J.E., Mason, E., Newby, H., et al. (2008) Countdown to 2015 for maternal, newborn, and child survival: The 2008 report on tracking coverage of interventions. Lancet, 371, 1247-1258. doi:10.1016/S0140-6736(08)60559-0

[5] Lawn, J.E., Cousens, S. and Zupan, J. (2005) 4 million 
neonatal deaths: When? Where? Why? Lancet, 365, 891900. doi:10.1016/S0140-6736(05)71048-5

[6] Darmstadt, G.L., Bhutta, Z.A., Cousens, S., Adam, T., Walker, N. and de Bernis, L. (2005) Evidence-based, costeffective interventions: How many newborn babies can we save? Lancet neonatal survival steering team. Lancet, 365, 977-988. doi:10.1016/S0140-6736(05)71088-6

[7] Lawn, J.E., Cousens, S., Bhutta, Z.A., Darmstadt, G.L., Martines, J., Paul, V., et al. (2004) Why are 4 million babies dying each year? Lancet, 364, 399-401. doi:10.1016/S0140-6736(04)16783-4

[8] Bang, A., Paul, V., Reddy, H. and Baitule, S. (2005) Why do neonates die in rural Gadchiroli, India? (Part I): Primary causes of death assigned by neonatologist based on prospectively observed records. Journal of Perinatology, 25, S29-S34. doi:10.1038/sj.jp.7211269

[9] Dutta, A.K. (2009) Home-based newborn care: How effective and feasible? Indian Pediatrics, 46, 835-840.

[10] Marsh, D.R., Darmstadt, G.L., Moore, J., Daly, P., Oot, D. and Tinker, A. (2002) Advancing newborn health and survival in developing countries: A conceptual framework. Journal of Perinatology, 2, 572-576. doi:10.1038/sj.jp.7210793

[11] Campbell, O.M. and Graham, W.J. (2006) Strategies for reducing maternal mortality: Getting on with what works. Lancet, 368, 1284-1299. doi:10.1016/S0140-6736(06)69381-1

[12] Khan, M.H., Khan, F., Noman, N., Hashmi, G., Gul1, S., Ali, A. and Babar, K.S. (2006) Essential newborn care practice in hospital versus home deliveries. Gomal Journal of Medical Sciences, 4, 1.

[13] Graneheim, U.H. and Lundman, B. (2004) Qualitative content analysis in nursing research: Concepts, procedures and measures to achieve trustworthiness. Nurse Education Today, 24, 105-112. doi:10.1016/j.nedt.2003.10.001

[14] Thaddeus, S. and Maine, D. (1991) Too far to walk: Maternal mortality in context. Women's Global Network for Reproductive Rights, 36, 22-24.

[15] Thaddeus, S. and Maine, D. (1994) Too far to walk: Maternal mortality in context. Social Science and Medicine, 38, 1091-1110. doi:10.1016/0277-9536(94)90226-7

[16] Kesterton, A.J. and Cleland, J. (2009) Neonatal care in rural Karnataka: Healthy and harmful practices, the potential for change. BMC Pregnancy and Childbirth, 9, 20. doi:10.1186/1471-2393-9-20

[17] Jeffery, R. and Jeffery, P.M. (1993) Traditional birth attendants in rural North India: The social organization of childbearing. Knowledge, power, and practice: The anthropology of medicine in everyday life. Nova Science Publishers, Inc., New York.

[18] Pinto, S. (2008) Where there is no midwife: Birth and loss in rural India. Berghahn Books, New York.

[19] World Health Organization (1996) Essential newborn care: A report of a technical working group. World Health Organization, Geneva.

[20] Ambe, P., Bello, M., Yahaya, S.J. and Omotara, B.A. (2009) Umbilical cord care practices in Konduga local government area of Borno State North-Eastern Nigeria The Internet Journal of Tropical Medicine, 5, 2.

[21] Darmstadt, G.L., Hassan, M., Balsara, Z.P., Winch, P.J., Gipson, R. and Santosham, M. (2009) Impact of clean delivery-kit use on newborn umbilical cord and maternal puerperal infections in Egypt. Journal of Health Population and Nutrition, 2, 6746-6754.

[22] Baqui, A.H., Williams, E.K., Darmstadt, G.L., Kumar, V., Kiran, T.U., Panwar, D., Sharma, R.K., et al. (2007) Newborn care in rural Uttar Pradesh. Indian Journal of Pediatrics, 74, 241-247. doi:10.1007/s12098-007-0038-6

[23] Manandhar, D.S., Osrin, D., Shrestha, B.P., Mesko, N., Morrison, J., Tumbahangphe, K.M., Tamang, S., et al. (2004) Effect of a participatory intervention with women's groups on birth outcomes in Nepal: Cluster-randomised controlled trial. Lancet, 364, 970-979. doi:10.1016/S0140-6736(04)17021-9

[24] Nandan, D. and Mishra, S.K. (1996) Delivery practices in west Uttar Pradesh. Indian Journal of Public Health, 40, 20-21.

[25] Osrin, D., Tumbahangphe, K.M., Shrestha, D., Mesko, N., Shrestha, B.P., Manandhar, M.K., Standing, H., Manandhar, D.S. and De L. Costello, A.M. (2002) Cross sectional, community based study of care of newborn infants in Nepal. British Medical Journal, 325, 1063. doi:10.1136/bmj.325.7372.1063

[26] Darmstat, G.L., Kumar, V., Yadav, R., Singh, V., Singh, P., Mohanty, S., Baqui, A.H., et al. (2006) Introduction of community-based skinto-skin care in rural Uttar Pradesh, India. Journal of Perinatology, 26, 597-604. doi:10.1038/sj.jp.7211569

[27] Edmond, K.M., Zandoh, C., Quigley, M.A., Amenga-Etego, S., Owusu-Agyei, S. and Kirkwood, B.R. (2006) Delayed breast-feeding initiation increases risk of neonatal mortality. Pediatrics, 117, 380-386. doi:10.1542/peds.2005-1496

[28] Sharma, R.K. (2010) Newborn care among tribes of central India experiences from micro level studies. Social Change, 40, 117-137. doi:10.1177/004908571004000202

[29] Huffman, S.L., Zehner, E.R. and Victora, C. (2001) Can improvements in breast-feeding practices reduce neonatal mortality in developing countries? Midwifery, 17, 80-92. doi:10.1054/midw.2001.0253

[30] Fikree, F.F., Ali, T.S., Durocher, J.M. and Rahbar, M.H. (2005) Newborn care practices in low socioeconomic settlements of Karachi, Pakistan. Social Science and Medicine, 60, 911-921. doi:10.1016/j.socscimed.2004.06.034

[31] Holman, D.J. and Grimes, M.A. (2001) Colostrum feeding behavior and initiation of breast-feeding in rural Bangladesh. Journal of Biosocial Science, 33, 139-154. doi:10.1017/S0021932001001390

[32] Choudhury, A.M., Nargis, S., Mollah, A.H., Kabir, L.M. and Sarkar, R.N. (2010) Determination of risk factors of neonatal pneumonia. Mymensingh Medical Journal, 1, 323-329.

[33] Shah, B.D. and Dwivedi, L.K. (2011) Causes of neonatal deaths among tribal women in Gujarat, India. Population Research and Policy Review, 30, 517-536. 
doi:10.1007/s11113-010-9199-5

[34] Williams, E.K., Hossain, M.B., Sharma, R.K., Kumar, V., Pandey, C.M. and Baqui, A.H. (2008) Birth interval and risk of still birth or neonatal death: Findings from rural North India. Journal of Tropical Pediatrics, 54, 321-327.

$$
\text { doi:10.1093/tropej/fmn027 }
$$

[35] Agarwal, S., Agarwal, A., Bansal, A.K., Agarwal, D.K. and Agarwal, K.N. (2002) Birth weight patterns in rural undernourished pregnant women. Indian Pediatrics, 39, 244-253. 